\title{
Experimental study into carbon dioxide solubility and species distribution in aqueous alkanolamine solutions
}

\author{
H. Yamada, T. Higashii, F. A. Chowdhury, K. Goto \& S. Kazama \\ Research Institute of Innovative Technology for the Earth, Japan
}

\begin{abstract}
We investigated the solubility of $\mathrm{CO}_{2}$ in aqueous solutions of alkanolamines at $40^{\circ} \mathrm{C}$ and $120^{\circ} \mathrm{C}$ over $\mathrm{CO}_{2}$ partial pressures ranging from a few $\mathrm{kPa}$ to $100 \mathrm{kPa}$ to evaluate the potential for $\mathrm{CO}_{2}$ capture from flue gas. $\mathrm{CO}_{2}$ capacities were compared between monoethanolamine, $\mathrm{N}$-ethyl ethanolamine and $\mathrm{N}$-isopropyl ethanolamine. Speciation analyses were conducted in the alkanolamine solutions at different $\mathrm{CO}_{2}$ loadings by accurate quantitative ${ }^{13} \mathrm{C}$ nuclear magnetic resonance spectroscopy. $\mathrm{N}$-isopropyl ethanolamine showed a large capacity for $\mathrm{CO}_{2}$ because of the formation of bicarbonate. However, we also found that at a lower $\mathrm{CO}_{2}$ loading a significant amount of carbamate was present in the aqueous $\mathrm{N}$-isopropyl ethanolamine solutions.

Keywords: carbon capture, amine absorbent, $\mathrm{CO}_{2}$ solubility, vapour-liquid equilibrium, nuclear magnetic resonance.
\end{abstract}

\section{Introduction}

Carbon capture and storage is of central importance for the reduction of anthropogenic $\mathrm{CO}_{2}$ emissions in the atmosphere. Amine scrubbing is the most promising and currently applicable technology used in an industrial scale for the capture of $\mathrm{CO}_{2}$ from a gas stream [1]. To maximise the capture efficiency and to reduce energy costs we previously developed $\mathrm{CO}_{2}$ capture systems and high performance $\mathrm{CO}_{2}$ absorbents [2-5]. Recently, we demonstrated that hindered amino alcohols for the promotion of $\mathrm{CO}_{2}$ capture can be developed by rational molecular design and by the placement of functional groups $[4,5]$.

For aqueous solutions of primary and secondary amines the $\mathrm{CO}_{2}$ absorption proceeds by the formation of a carbamate anion or a bicarbonate anion. It is well 
known that bicarbonate formation occurs at a lower rate than carbamate formation while bicarbonate formation results in a large $\mathrm{CO}_{2}$ absorption capacity [3]. However, we found that some 'moderately' hindered amines have combined desirable characteristics such as high rate and large capacity for $\mathrm{CO}_{2}$ absorption $[4,5]$. In this work, we investigated aqueous solutions of alkanolamines by isothermal vapour-liquid equilibrium (VLE) measurements for $\mathrm{CO}_{2}$ and by ${ }^{13} \mathrm{C}$ nuclear magnetic resonance (NMR) spectroscopic analyses. The results provide insights into the absorption mechanism and the relationship between the absorption properties and molecular structures of alkanolamines.

\section{Experimental}

\subsection{Alkanolamines}

Alkanolamines of ca. $99 \%$ purity were purchased from various chemical companies and used without further purification. The molecular structures of the alkanolamines investigated in this work are shown in Figure 1.<smiles>NCCO</smiles>

MEA<smiles>CCNCCO</smiles>

EAE<smiles>CC(C)NCCO</smiles>

IPAE

Figure 1: $\quad$ Molecular structures of the investigated amines.

\subsection{Vapour-liquid equilibrium}

VLE data were measured at $40^{\circ} \mathrm{C}$ and $120^{\circ} \mathrm{C}$ over various $\mathrm{CO}_{2}$ partial pressures ranging from a few $\mathrm{kPa}$ to ca. $100 \mathrm{kPa}$ to compare their $\mathrm{CO}_{2}$ capture potentials. Approximately $700 \mathrm{~mL}$ of the $30 \mathrm{wt} \%$ aqueous amine solutions were fed into an autoclave, which was then purged with $\mathrm{N}_{2}$. During the experiment, the temperature-controlled solutions were agitated by a mechanical stirrer. The $\mathrm{CO}_{2} / \mathrm{N}_{2}$ gas mixture was concentration-controlled using mass flow controllers and the mixture was supplied to the autoclave after flowing through a watersaturator. The outlet gas was monitored by an infrared $\mathrm{CO}_{2}$ analyser (VA-3001, Horiba) after flowing through a condenser. An equilibrium was obtained when the $\mathrm{CO}_{2}$ analyser indicated a constant $\mathrm{CO}_{2}$ concentration $( \pm 0.01 \%)$. To analyse the equilibrium data the temperature and total pressure in the gas phase were measured while the amount of $\mathrm{CO}_{2}$ in the liquid phase sample drawn from the autoclave was measured by a total organic carbon analyser (TOC- $\mathrm{V}_{\mathrm{CSH}}$, Shimadzu) and the maximum coefficient of variation was $1.5 \%$. 


\subsection{Nuclear magnetic resonance}

$\mathrm{CO}_{2}$ saturated solutions were prepared by flowing the $\mathrm{CO}_{2}$ gas at a rate of $500 \mathrm{~mL} / \mathrm{min}$ into $75 \mathrm{~g}$ of $30 \mathrm{wt} \%$ aqueous alkanolamine solutions at room temperature and atmospheric pressure for $15 \mathrm{~min}$. The $\mathrm{CO}_{2}$ loading was lowered by mixing the $30 \mathrm{wt} \%$ aqueous alkanolamine solution and the $\mathrm{CO}_{2}$ saturated solution.

The prepared sample solutions were analysed with a NMR spectrometer (DRX-500, Bruker) at $30^{\circ} \mathrm{C}$. A double-walled sample tube was used with $\mathrm{C}_{6} \mathrm{D}_{6}$ as the lock solvent and $\mathrm{Si}\left(\mathrm{CH}_{3}\right)_{4}$ as the internal standard to retain the sample concentration. ${ }^{13} \mathrm{C}$ NMR spectra were recorded at $125.8 \mathrm{MHz}$. Quantitative spectra were obtained using the inverse-gated decoupling technique with a pulse angle of $90^{\circ}$, a delay time of $60 \mathrm{~s}$ and 512 scans. ${ }^{13} \mathrm{C}$ spin-lattice relaxation times were measured by the inversion recovery method. The $\mathrm{CO}_{2}$ loadings of the sample solutions were also quantified by the TOC analyser.

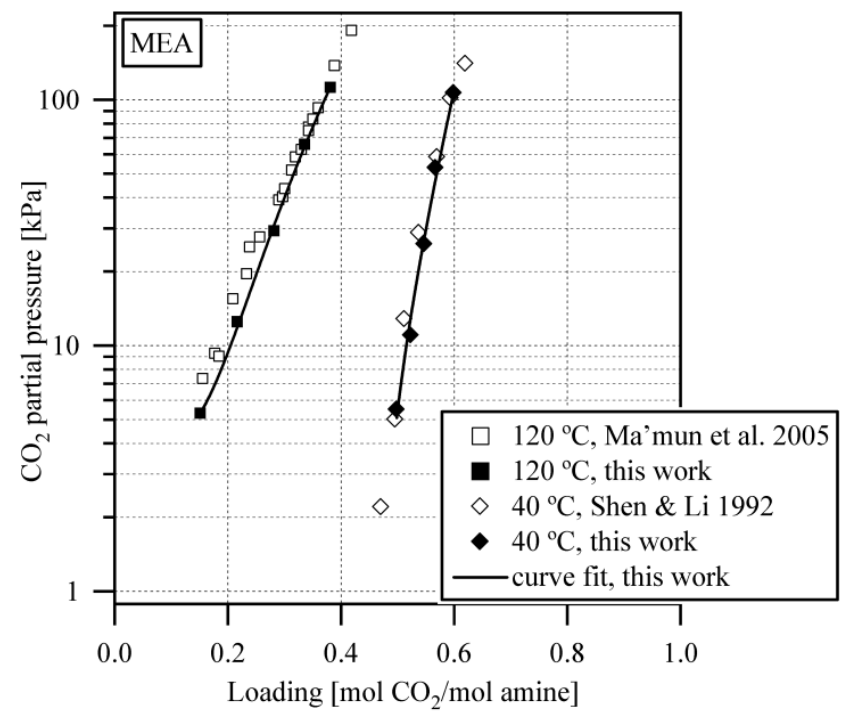

Figure 2: Equilibrium partial pressure of $\mathrm{CO}_{2}$ in $30 \mathrm{wt} \%$ aqueous solutions of monoethanolamine.

\section{Results and discussion}

\section{1 $\mathrm{CO}_{2}$ solubility}

Figures 2 and 3 show the equilibrium solubility data of $\mathrm{CO}_{2}$ in $30 \mathrm{wt} \%$ aqueous solutions of monoethanolamine (MEA), 2-(ethylamino)ethanol (EAE) and 2-(isopropylamino)ethanol (IPAE). The loading $(\alpha)$ represents the molar ratio of 
loaded $\mathrm{CO}_{2}$ to the total amine in the liquid phase. The solubility data in $30 \mathrm{wt} \%$ aqueous MEA solutions were measured at $120^{\circ} \mathrm{C}$ by Ma'mun et al. [6] and at $40^{\circ} \mathrm{C}$ by Shen and Li. [7], and these are also shown in Figure 2 for comparison. This data agrees well with the data obtained in this work.

As shown in Figures 2 and 3, at a typical temperature for $\mathrm{CO}_{2}$ absorption such as $40^{\circ} \mathrm{C}$ the aqueous solutions of $\mathrm{N}$-substituted ethanolamines show higher $\mathrm{CO}_{2}$ solubilities than that for the conventional aqueous MEA solutions in the $\mathrm{CO}_{2}$ partial pressure range of $6 \mathrm{kPa}$ to $100 \mathrm{kPa}$. On the other hand, the aqueous MEA solution has higher $\mathrm{CO}_{2}$ solubility than the aqueous EAE and IPAE solutions at a typical temperature for the $\mathrm{CO}_{2}$ stripping process of $120^{\circ} \mathrm{C}$ and at a $\mathrm{CO}_{2}$ partial pressure of $100 \mathrm{kPa}$ : the $\mathrm{CO}_{2}$ loadings were $0.4,0.3$ and 0.2 for MEA, EAE and IPAE, respectively.

The solubility data from these experiments were determined by curve fitting. A power function satisfactorily fits the data in the studied $\mathrm{CO}_{2}$ partial pressure range. The fitted curves are also shown in Figures 2 and 3.

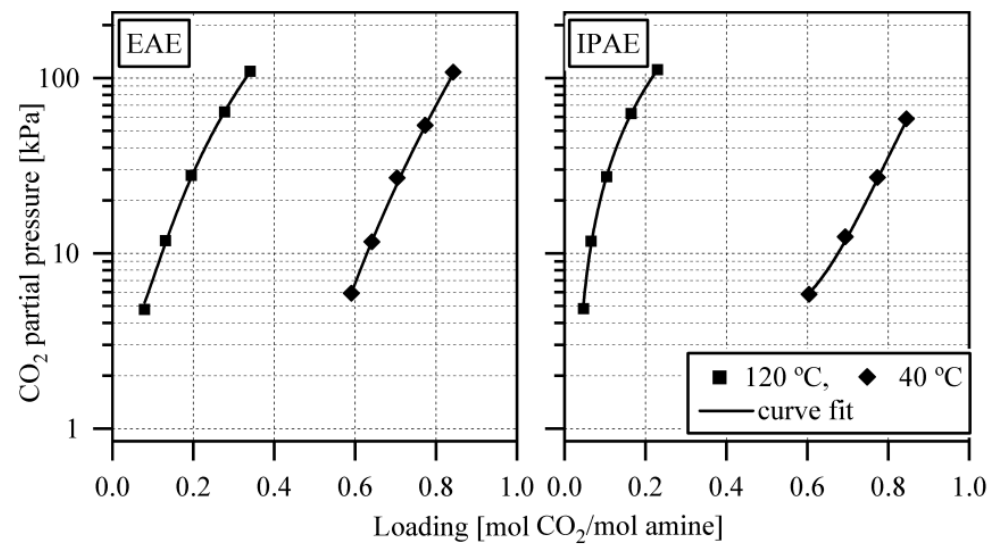

Figure 3: Equilibrium partial pressure of $\mathrm{CO}_{2}$ in $30 \mathrm{wt} \%$ aqueous solutions of 2-(ethylamino)ethanol and 2-(isopropylamino)ethanol.

\subsection{Cyclic $\mathrm{CO}_{2}$ capacity}

The VLE data enables the calculation of the cyclic $\mathrm{CO}_{2}$ capacity $(\Delta \alpha)$, i.e., the maximum loading difference between the $\mathrm{CO}_{2}$ rich solution in the absorber and the $\mathrm{CO}_{2}$ lean solution in the stripper. Using conditions of $40^{\circ} \mathrm{C}$ and a $10 \mathrm{kPa} \mathrm{CO}$ partial pressure for the absorption process, and $120^{\circ} \mathrm{C}$ as well as a $100 \mathrm{kPa} \mathrm{CO}$ partial pressure for the stripping process we define the cyclic $\mathrm{CO}_{2}$ capacity as follows:

$$
\Delta \alpha=\alpha_{40{ }^{\circ} \mathrm{C}, 10 \mathrm{kPa}}-\alpha_{120{ }^{\circ} \mathrm{C}, 100 \mathrm{kPa}} .
$$

As shown in Figures 2 and 3 , the aqueous IPAE solutions have a larger cyclic $\mathrm{CO}_{2}$ capacity than MEA and EAE because of the high absorbability of $\mathrm{CO}_{2}$ under the absorber conditions and the high desorbability of $\mathrm{CO}_{2}$ under the 
stripper conditions. The calculated cyclic capacities are $0.14,0.30$ and 0.46 for MEA, EAE and IPAE, respectively, indicating that the substituent adjacent to the amino group drastically affects the $\mathrm{CO}_{2}$ capacity.

$30 \mathrm{wt} \%$ aqueous solutions of MEA, EAE and IPAE contain 4.9, 3.4 and 2.9 moles of amine per kilogram, respectively. This means that MEA has an advantage because of its low molar weight compared with the $\mathrm{CO}_{2}$ capacity between the solutions containing the same mass of amines. However, IPAE still has the largest cyclic $\mathrm{CO}_{2}$ capacity in terms of capacity per mass of absorbent: 31,44 and 59 grams of $\mathrm{CO}_{2}$ per kilogram of absorbent were found for MEA, EAE and IPAE, respectively.

\subsection{Quantitative ${ }^{13}$ C NMR}

By the inversion recovery method we confirmed that the ${ }^{13} \mathrm{C}$ spin-lattice relaxation time is the longest for the carbon of carbamate or the carbon of carbonate (ca.10 s) among the various carbons in the $\mathrm{CO}_{2}$ loaded aqueous alkanolamine solutions. For quantitative ${ }^{13} \mathrm{C}$ NMR measurements, a delay time allowing the system to return to thermal equilibrium in the standard inversegated decoupling sequence should be at least 5 times longer than the spin-lattice relaxation time [8]. Therefore, the delay time was determined to be $60 \mathrm{~s}$ in this work.

The quantitative ${ }^{13} \mathrm{C}$ NMR spectra were confirmed by the TOC results. The deviation of the $\mathrm{CO}_{2}$ loading between the ${ }^{13} \mathrm{C}$ NMR and the TOC analysis results was at most 0.01 in this work.

\subsection{Species distribution}

The $\mathrm{CO}_{2}$ saturated solutions of MEA, EAE and IPAE prepared at room temperature and under atmospheric pressure were analysed by ${ }^{13} \mathrm{C} \mathrm{NMR}$ and the $\mathrm{CO}_{2}$ loadings were found to be $0.56,0.72$ and 0.90 , respectively, as shown in Figures 4 and 5. Figure 4 also shows an interpretation of the peaks and the relative areas of the ${ }^{13} \mathrm{C}$ NMR spectra for the $\mathrm{CO}_{2}$ saturated solutions of MEA and EAE. The carbamate, carbonate $\left(\mathrm{CO}_{3}{ }^{2-}\right.$ and $\left.\mathrm{HCO}_{3}{ }^{-}\right)$and amine (neutral amine and protonated amine) species were unambiguously identified in the spectra and no other species were detected except for trace impurities. The errors in the peak areas of the spectra were estimated to be at most $3 \%$ on the basis of the standard deviations of peak areas from the different carbons of the same amine species. It should be noted that one peak was detected for the carbon of the carbonate $\left(\mathrm{HCO}_{3}{ }^{-}\right.$and $\left.\mathrm{CO}_{3}{ }^{2-}\right)$ species in ${ }^{13} \mathrm{C}$ NMR because of the fast exchange of protons. It is not possible to distinguish between amines and protonated amines from ${ }^{13} \mathrm{C}$ NMR spectra for this same reason.

\subsection{Carbamate yield}

As shown in Figures 4 and 5, peaks that result from absorbed $\mathrm{CO}_{2}$ were observed at 161-165 ppm. The yield of carbamate, which is defined as the molar ratio of carbamate to absorbed $\mathrm{CO}_{2}$ was obtained from those peak areas, e.g., 0.74 was 


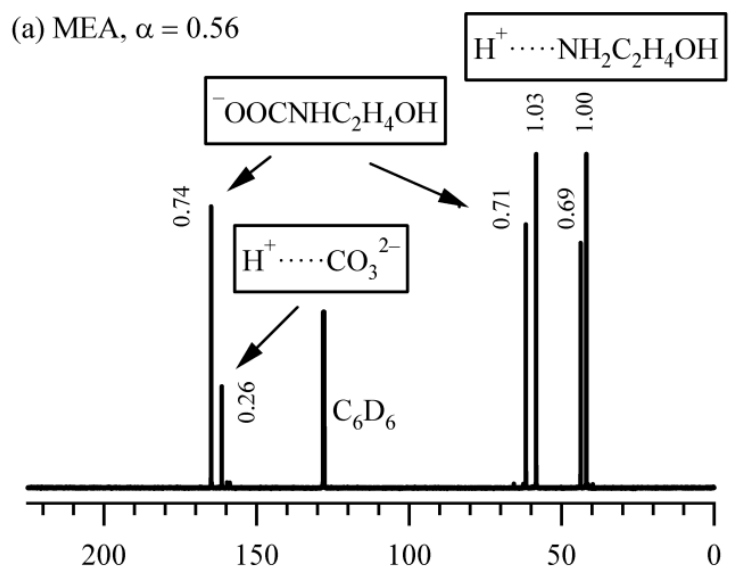

(b) EAE, $\alpha=0.72$

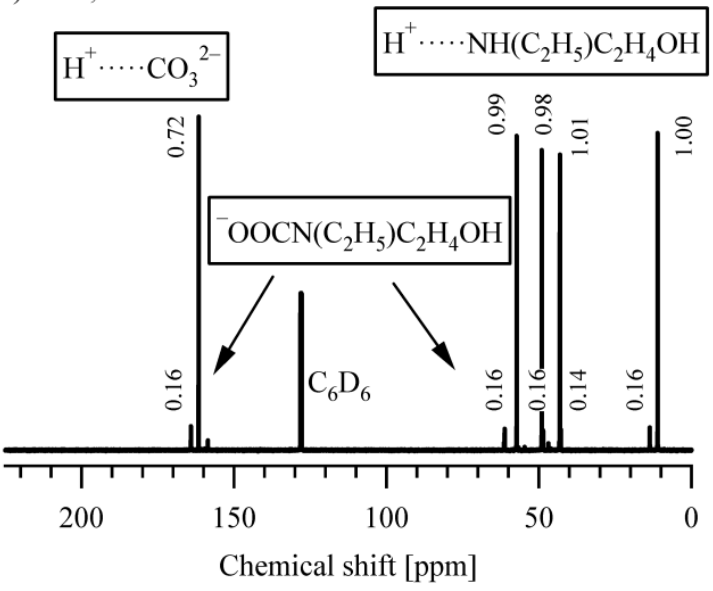

Figure 4: ${ }^{13} \mathrm{C} \quad \mathrm{NMR}$ spectra of $30 \quad \mathrm{wt} \%$ aqueous solutions of (a) monoethanolamine and (b) 2-(ethylamino)ethanol at $\mathrm{CO}_{2}$ loadings of 0.56 and 0.72 , respectively, with peak interpretations and the relative values for the peak areas.

obtained at a $\mathrm{CO}_{2}$ loading of 0.56 and at $30^{\circ} \mathrm{C}$ in the aqueous MEA solutions. This value is close to previous data by Jakobsen et al. [9]: $0.76(0.79)$ at a $\mathrm{CO}_{2}$ loading of 0.59 and at $40^{\circ} \mathrm{C}\left(20^{\circ} \mathrm{C}\right)$ in $30 \mathrm{wt} \%$ aqueous MEA solutions. Böttinger et al. [10] also carried out quantitative speciation of $30 \mathrm{wt} \%$ aqueous MEA solutions by online NMR spectroscopy where the carbamate yield was 0.57 at a $\mathrm{CO}_{2}$ loading of 0.77 and at $40^{\circ} \mathrm{C}$. These results show that for aqueous MEA solutions the carbamate products dominate the carbonate and carbamate products even at a relatively high $\mathrm{CO}_{2}$ loading. 
(a) IPAE, $\alpha=0.90$

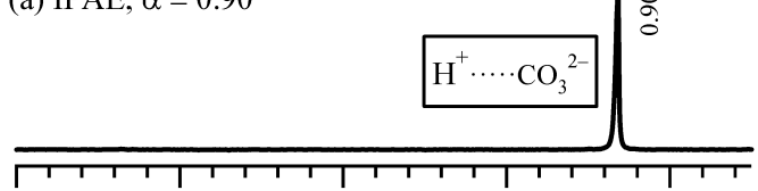

(b) IPAE, $\alpha=0.38$

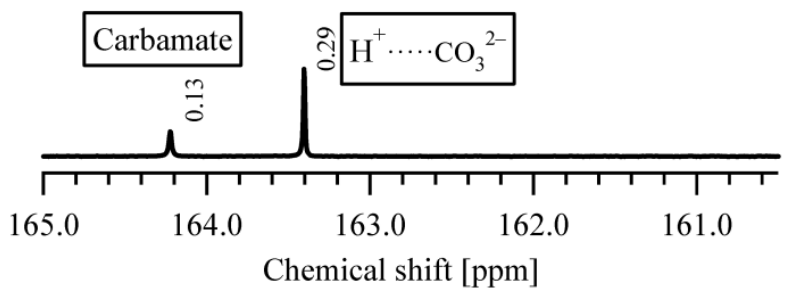

Figure 5: $\quad{ }^{13} \mathrm{C}$ NMR spectra of $\mathrm{CO}_{2}$-loaded $30 \mathrm{wt} \%$ aqueous solutions of 2(isopropylamino)ethanol at $\mathrm{CO}_{2}$ loadings of (a) 0.90 and (b) 0.38 with peak interpretations for the carbamate and carbonate species.

For secondary alkanolamines, the carbamate yield decreases with an increase in the steric hindrance of the substituted amino group. The carbamate yield was 0.18 at a $\mathrm{CO}_{2}$ loading of 0.72 for EAE, as shown in Figure 4. Alkanolamines with a more sterically hindered amino group such as IPAE give lower yields of carbamate and higher loadings. The carbamate yield was 0.00 at a $\mathrm{CO}_{2}$ loading of 0.90 in IPAE, as shown in Figure 5.

For the sterically hindered primary amine, 2-amino-2-methyl-1-propanol (AMP), it has been confirmed by previous ${ }^{13} \mathrm{C}$ NMR studies that $\mathrm{CO}_{2}$ absorption in aqueous AMP solutions predominantly gives the bicarbonate anion at equilibrium [3,11]. Ciftja et al. [11] performed speciation on $30 \mathrm{wt} \%$ aqueous solutions of AMP with different amounts of $\mathrm{CO}_{2}$ at $25^{\circ} \mathrm{C}$ where the carbamate yield was at most 0.03 in the loading range from 0.12 to 0.62 . Even though the carbamate anion is a very minor product, carbamate formation is considered to play an important role in $\mathrm{CO}_{2}$ absorption by AMP solutions [12].

At a loading of 0.38 in IPAE the carbamate yield was as high as 0.31 , as shown Figure 5. This finding indicates that significant carbamate formation occurs for IPAE at a lower $\mathrm{CO}_{2}$ loading despite its sterically hindered amino group and high capacity.

\subsection{Reaction mechanism}

In aqueous solutions of primary and secondary amines, $\mathrm{CO}_{2}$ is absorbed by the formation of carbamate or bicarbonate anions

$$
2 \mathrm{BH}+\mathrm{CO}_{2} \leftrightarrow \mathrm{BCOO}^{-}+\mathrm{BH}_{2}^{+},
$$




$$
\mathrm{BH}+\mathrm{CO}_{2}+\mathrm{H}_{2} \mathrm{O} \leftrightarrow \mathrm{HCO}_{3}^{-}+\mathrm{BH}_{2}^{+} .
$$

For sterically hindered amines the carbamate is not stable and may be converted into bicarbonate through hydrolysis

$$
\mathrm{BCOO}^{-}+\mathrm{H}_{2} \mathrm{O} \leftrightarrow \mathrm{HCO}_{3}^{-}+\mathrm{BH} .
$$

Generally, the reaction shown in eqn. (2) occurs faster than the reaction in eqn. (3). Bicarbonate formation stoichiometrically requires $1 \mathrm{~mol}$ of amine per mole of $\mathrm{CO}_{2}$ and allows for a large $\mathrm{CO}_{2}$ capacity whereas carbamate formation requires $2 \mathrm{~mol}$ of amine per mole of $\mathrm{CO}_{2}$.

Recently, we performed a quantum chemical analysis for $\mathrm{CO}_{2}$ absorption into aqueous solutions of IPAE and showed that carbamate forms easily via a zwitterion intermediate

$$
\mathrm{BH}+\mathrm{CO}_{2} \leftrightarrow \mathrm{BH}^{+} \mathrm{COO}^{-} .
$$

However, the carbamate decomposes by the reverse reaction of eqn. (2) rather than by the reaction shown in eqn. (4). As a final product, bicarbonate forms by the reaction shown in eqn. (3) in a single-step [4].

The experimental results in this work show a large cyclic $\mathrm{CO}_{2}$ capacity for IPAE because of bicarbonate formation. However, it has also been found that a significant amount of IPAE carbamate is formed in a low $\mathrm{CO}_{2}$ loading regime. These results support the above-mentioned absorption mechanisms.

\section{Summary}

The equilibrium solubility data of $\mathrm{CO}_{2}$ into $30 \mathrm{wt} \%$ aqueous solutions of monoethanolamine (MEA), 2-(ethylamino)ethanol (EAE) and 2(isopropylamino)ethanol (IPAE) were determined at $40^{\circ} \mathrm{C}$ and $120^{\circ} \mathrm{C}$ over $\mathrm{CO}_{2}$ partial pressures ranging from a few $\mathrm{kPa}$ to $100 \mathrm{kPa}$. Differences in a $\mathrm{CO}_{2}$ loading under $10 \mathrm{kPa} \mathrm{CO}$ partial pressure at $40^{\circ} \mathrm{C}$ and in $\mathrm{CO}_{2}$ loading under $100 \mathrm{kPa} \mathrm{CO}$ partial pressure at $120^{\circ} \mathrm{C}$ were found to be $0.14,0.30$ and $0.46 \mathrm{~mol}$ $\mathrm{CO}_{2} / \mathrm{mol}$ amine for MEA, EAE and IPAE, respectively. By quantitative ${ }^{13} \mathrm{C}$ nuclear magnetic resonance spectroscopy we showed that carbamate predominantly forms in the $\mathrm{CO}_{2}$ saturated aqueous MEA solutions whereas it is an undetectable minor product in the $\mathrm{CO}_{2}$ saturated aqueous IPAE solutions. However, a significant amount of carbamate was found in the aqueous IPAE solutions at a lower $\mathrm{CO}_{2}$ loading. These findings agree with the reaction mechanism proposed by a quantum chemical analysis and explain the properties of the absorbents.

\section{References}

[1] Rochelle, G.T., Amine scrubbing for $\mathrm{CO}_{2}$ capture. Science, 325(5948), pp. 1652-1654, 2009. 
[2] Goto, K., Okabe, H., Shimizu, S., Onoda, M. \& Fujioka, Y., Evaluation method of novel absorbents for $\mathrm{CO}_{2}$ capture. Energy Procedia, 1, pp. 1083-1089, 2009.

[3] Yamada, H., Shimizu, S., Okabe, H., Matsuzaki, Y., Chowdhury, F.A. \& Fujioka, Y., Prediction of the basicity of aqueous amine solutions and the species distribution in the amine $-\mathrm{H}_{2} \mathrm{O}-\mathrm{CO}_{2}$ system using the COSMO-RS method. Industrial \& Engineering Chemistry Research, 49(5), pp. 2449-2455, 2010.

[4] Yamada, H., Matsuzaki, Y., Okabe, H., Shimizu, S. \& Fujioka, Y., Quantum chemical analysis of carbon dioxide absorption into aqueous solutions of moderately hindered amines. Energy Procedia, 4, pp. 133-139, 2011.

[5] Chowdhury, F.A., Okabe, H., Yamada, H., Onoda, M. \& Fujioka, Y., Synthesis and selection of hindered new amine absorbents for $\mathrm{CO}_{2}$ capture. Energy Procedia, 4, pp. 201-208, 2011.

[6] Ma'mun, S., Nilsen, R. \& Svendsen, H.F., Solubility of carbon dioxide in 30 mass \% monoethanolamine and 50 mass \% methyldiethanolamine solutions. Journal of Chemical \& Engineering Data, 50(2), pp. 630-634, 2005.

[7] Shen K.P. \& Li, M.H., Solubility of carbon dioxide in aqueous mixtures of monoethanolamine with methyldiethanolamine. Journal of Chemical \& Engineering Data, 37(1), pp. 96-100, 1992.

[8] Giraudeau, P., Wang, J.L. \& Baguet, É., Improvement of the inverse-gateddecoupling sequence for a faster quantitative analysis by ${ }^{13} \mathrm{C} N M R$. Comptes Rendus Chimie, 9(3), pp. 525-529, 2006.

[9] Jakobsen, J.P., Krane, J. \& Svendsen, H.F., Liquid-phase composition determination in $\mathrm{CO}_{2}-\mathrm{H}_{2} \mathrm{O}$-alkanolamine systems: an NMR study. Industrial \& Engineering Chemistry Research, 44(26), pp. 9894-9903, 2005.

[10] Böttinger, W., Maiwald, M. \& Hasse, H., Online NMR spectroscopic study of species distribution in $\mathrm{MEA}-\mathrm{H}_{2} \mathrm{O}-\mathrm{CO}_{2}$ and $\mathrm{DEA}-\mathrm{H}_{2} \mathrm{O}-\mathrm{CO}_{2}$. Fluid Phase Equilibria, 263(2), pp. 131-143, 2008.

[11] Ciftja, A.F., Hartono, A., da Silva, E.F., \& Svendsen, H.F., Study on carbamate stability in the $\mathrm{AMP} / \mathrm{CO}_{2} / \mathrm{H}_{2} \mathrm{O}$ system from ${ }^{13} \mathrm{C}-\mathrm{NMR}$ spectroscopy. Energy Procedia, 4, pp. 614-620, 2011.

[12] Yamada, H., Matsuzaki, Y., Higashii, T. \& Kazama, S., Density functional theory study on carbon dioxide absorption into aqueous solutions of 2amino-2-methyl-1-propanol using a continuum solvation model. Journal of Physical Chemistry A, 115(14), pp. 3079-3086, 2011. 